\title{
Balancing the Scales: Harmonizing Heritage Management, Site-Specific Research, and the Mitigation of Adverse Effects
}

\author{
RICHARD H. WILSHUSEN \\ Colorado State University
}

\begin{abstract}
The Southern Colorado River Basin context published in 1999 offered a remarkable overview of Mesa Verde regional archaeology. It reviewed the available research for each main period of occupation and, at the end of each summary, outlined some of the most important questions for future research. For the late Basketmaker and early Pueblo periods many of those research questions have been addressed or are now outdated. Current questions are not just about research, but also about how to balance long-term heritage management goals with site-specific research. The accelerating loss of cultural landscape to irrigated fields, energy development, and the expansion of country homes requires us to both broaden the scope of our preservation planning and the scale of our research questions to the landscape level. In this review I propose changes to the extent and nature of the Southern Colorado River Basin context area, as well as offer amendments to the previous period chronologies based on what we have learned. Lastly, I suggest an array of research themes for future work. Although this is not a state-approved context, it is offered as a challenge to us-whether we represent the state, a federal agency, a university, or a CRM firm-to think big about the research we do in the greater Mesa Verde region.
\end{abstract}

Keywords: Mesa Verde region, late Basketmaker, early Pueblo, heritage management, landscape archaeology

\section{The 1999 Southern Colorado Context, Site Significance, and New Challenges}

Two decades after its publication the Southern Colorado River Basin context (Lipe, Varien, and Wilshusen 1999) remains striking in its ambition to offer a data-rich resource for evaluating new archaeological discoveries and designing new research. Over time it has proven to be useful to government archaeologists, cultural resource management (CRM) professionals, those in the academy, and even highly motivated avocational archaeologists. In the introduction, Lipe (1999) laid out the criteria for site evaluations, clarified our archaeological research orientation (what Lipe called "expanded processual"), and discussed the challenges of balancing public benefit with resource conservation. We sought to describe the broader themes and patterns of history so as to be useful to a wider audience, but also with sufficient specificity to aid in National Register of Historic Places (NRHP) eligibility decision-making. Additionally, we were newly aware of the need for mutually beneficial collaboration and effective consultation with Native American tribes in archaeological research and preservation planning.

By bringing together and analyzing an immense amount of research data for each major temporal period, it was possible to characterize broad trends of change and stability. Themes such as population movement, regional site distribution, site types, subsistence strategies, and community organization 
were considered for each period; issues pertinent to making sense of a specific period, such as cultural identity and diversity in Pueblo I or violence and the Chaco connection in Pueblo II, were highlighted in each chapter. The overview took to heart the advice in National Register Bulletin 15 when it noted that:

The significance of a historic property can be judged and explained only when it is evaluated within its historic context. Historic contexts are those patterns, themes, or trends in history by which a specific occurrence, property, or site is understood and its meaning (and ultimately its significance) within history or prehistory is made clear [NRHP 1991:7].

Lipe (1999:1) emphasized that sites could be significant for their ties to an important event or pattern in this area's historical development (NRHP Criterion A); for their association with the life of an important person (Criterion B); or for characteristics of building form, style, engineering technique, materials, or method of construction that shaped this area's historic identity (Criterion C). Yet at that time archaeological sites were most often evaluated by their significance to offer new research information regarding the past (Criterion D), so much of the volume was focused on established site-centric research issues. We were just beginning to think about how to frame our site research within the larger context of the surrounding historic landscape (Anschuetz et al. 1999; Whittlesey 1997) and to recognize how an archaeological site might be significant under a variety of National Register criteria (e.g., Lipe 1996). Cultural and agricultural landscapes were mentioned in the chapter on Basketmaker III (Wilshusen 1999a:181, 191) and discussed in greater detail in the Pueblo I chapter (Wilshusen 1999b:219, 223-229, 233, 239), yet other than for recognizing landscape features such as shrines and great kivas or identifying the changing uses of the landscape this was a topic beyond the reach of our data and technical capabilities.

With modern site databases and tools such as geographic information systems (GIS), we can now focus our historic preservation efforts at a larger scale such as the landscape. If we are to make meaningful sense of the past, much less to have any recognizable elements of the historic landscape intact thirty years from now (Doelle et al. 2016), we must turn our attention to this level. To do this we need to embrace a range of National Register criteria beyond Criterion $\mathrm{D}$ and give weight to new research themes in our archaeological investigations and planning. We will only begin to understand the larger landscape when we finally move a portion of our mitigation efforts and preservation planning priorities to the level of districts or landscapes. Cultural landscapes often shape, and are shaped by, the events that have contributed to the broad patterns of our history (Criterion A). These landscapes equally can be molded and defined by the communities, buildings, shrines, and community centers that are distinctive of different periods of time (Criterion C). And great leaders in the past or innovative researchers in the present may have been associated with specific sites or research areas (Criterion B). Remembering the full range of significance criteria in our evaluations is critical as we transition to a cultural landscape approach in heritage management.

Given the immense amount of historic development and disturbance in this region, addressing the issue of "integrity," defined as the sufficiency or completeness of the preservation of a site, district, or landscape to be useful for future research or to convey its significance, will be challenging, but equally essential. Evaluating the integrity of a landscape is akin to the familiar task of evaluating site integrity; but, because the remnants of the ancient Pueblo landscape encompass both cultural and natural resources, the assessment of integrity is a bit more complicated. Ancient cultural landscapes will encompass fields, community centers, special use areas and resources, sacred sites, burial grounds, and other once interrelated features. The trick will be to design the means to weigh and evaluate the significance of the different components, and by extension the integrity, of the pieces that remain of any particular landscape.

There are plenty of models to guide us in the West, ranging from the historic landscapes of the silver mining communities in Nevada (Hardesty 2010) to the landscapes of San Clemente Island in California (Heilen et al. 2016). I am certain we will learn a great deal that is new about this context area simply by trying to define and evaluate what remains of this cultural landscape. I will focus 
solely on the late Basketmaker-early Pueblo period landscape in this article, so I can offer a few specific examples of how this might work. To implement this model, we would need to build significance models at the landscape level for each of the other main periods as well, as I discuss later. If we do this, we can transform heritage management by rebalancing the mitigation of the adverse effects of a project to consider both the sites and the larger landscape that potentially may be affected.

\section{Changing the Way We Do Business: Dealing with Current Development Challenges and Planning for the Future}

As we deliberate how to revitalize the 1999 context we must also remember that Colorado's overall preservation efforts are guided by a statewide historic preservation plan (History Colorado 2011). Although this plan lays out a general set of goals that inform the actions of the State Historic Preservation Office (SHPO), the State Archaeologist typically refers to the historic context documents for each area in making specific decisions regarding threats to sites due to development and long-term risks, or relative to the preservation needs of a region. In addition to context documents, archaeologists also sometimes use the National Register's Multiple Property Documentation Form (MPDF) to delineate historic districts or historic landscapes so that research and heritage management can be directed at a wider area (e.g., Bender 2011; Varien and Diederichs 2012). The present challenge is to begin to move to this more extensive scale of landscape documentation and a longer view of heritage management in our day-to-day decisionmaking. Our daily National Historic Preservation Act (NHPA) Section 106 choices regarding research, preservation, and sacrifice must balance our need for long-term heritage management at the landscape level with the demands for mitigation of adverse effects at the site-specific level.

The enormity of our losses of the ancient cultural landscape over the last two decades (Wilshusen 2018) has demonstrated that a reactive approach to making preservation choices is insufficient. It has left us with a haphazard array of historic properties and swathes of landscape that resemble a jigsaw puzzle of the past with only fragmentary portions of the picture left. We must begin to recognize and focus on what remains of those settlements, their long-abandoned fields, the kilns, gathering areas, and other shared community properties that might have encompassed the cultural landscape of an ancient community. With this knowledge we can begin to decide what is reasonable to consider for future preservation. This will allow us to pursue a broader strategy, one that recognizes the need to save a sufficiently appropriate sample or crosssection of our multi-layered cultural landscape for the future.

The risks to our present landscape will increase over time, and we must plan for them now. If we only consider climate change, we are already seeing dramatic losses of historic resources due to rising seas along our coasts (Anderson et al. 2017). Increasing episodes of extreme weather, recordsetting rainfall and floods, as well as vegetation changes and wildfires worldwide (Heilen, Altschul, and Lüth 2018) already are threatening the integrity of Colorado's historic resources. Landscape level planning will offer us the opportunity to anticipate these threats as we design a new paradigm for addressing the daily demands of mitigation decision-making.

By shifting our research and even some of our mitigation efforts to the landscape level we will face new risks, but this refocusing will also allow us to explore research topics and preservation options presently beyond our conventional way of doing CRM archaeology. We will make some mistakes in learning how to pursue a more balanced approach, but our losses will be far greater in the long term if we fail to incorporate a wider view now. Choices will have to be made as to where to place our efforts; but if we proactively make good choices, then important resource values will be preserved for future research and enjoyment. This article offers one proposal, one roadmap, on how to move forward. How we proceed will need to be debated, but a discussion needs at least one proposal to consider, so this review is offered in the hopes of starting the discussion in earnest.

I will draw upon, but not completely follow, the informal recommendations of Wyatt (2009) regarding the key topics for historic contexts, but with the caveat that this is offered as a proposal for consideration. The particulars of forms, such as the 
National Register's MPDF-which could be used to designate and describe a district, a larger landscape, or broad class of historic properties-will only be addressed in passing. The primary objective of this article is to challenge archaeologists working in this context region to recognize that we are at a critical moment in which we must increase the scale at which we set our research and preservation priorities. There are important questions that must be considered if we choose to pursue a larger-scale strategy, and we should begin this discussion as soon as feasible if we are to have a meaningful portion of this heritage-rich landscape for the future.

A shift in scale will require that we consider changes to our current CRM and heritage management practices as we pursue longer-term goals. We will need to seriously evaluate how to make trade-offs, such that we may forgo complete resurvey in certain areas or full documentation of lower priority resources in exchange for greater protection or creation of new heritage reserves in higher priority areas. Making changes to our current practices will be uncomfortable, but we must move from a piecemeal heritage management system that is based on documenting one potentially NRHPeligible site after another to a system that allots greater mitigation resources for long-term research or more encompassing and future-oriented preservation goals. These will be difficult questions to confront, but we must take them on if we are to ensure a meaningful fraction of what remains of the historic fabric of the late Basketmaker and early Pueblo occupations of the context area for future generations.

In the following section I propose changes to the geographic coverage and chronological periods defined in the 1999 context and also suggest some of the key research themes that might be emphasized in a new context. This is a starting point for consideration and discussion as we begin to shape a next set of digital historic contexts. In a later section I propose how we might begin to construct a heritage plan that would help in making mitigation decisions day-to-day as well as setting preservation objectives for the decade to come.

\section{An Initial Proposal for Discussion and Debate Among Archaeologists}

At the beginning let me make clear that this is a proposal for how we might obtain but one piece of what would need to be a six-part updated historic context for southwestern Colorado. I suggest here how we would update the context for a four-century period (A.D. 500-920) in this context area. We would need complementary contexts for five other periods: the Paleoindian through Archaic (pre-1000 B.C.), Basketmaker II (1000 B.C.-A.D. 500), Pueblo II and III (A.D. 920-1300), the post-Puebloan (A.D. 1300-1840), and Historic (A.D. 1840-1965). Two of these periods, the late Basketmaker-early Pueblo and later Pueblo period (Pueblo II and III), account for more than 90 percent of the total historic properties recorded in this area, so if we can agree on a way to update these two periods it is likely that the plans for the others will readily follow.

We must envision the cultural landscapes of these periods if we are ever to truly understand the ways in which past cultures made this region their home. We cannot understand a period or a culture just by looking at site after site. Instead we must begin to consider how certain non-residential sites were used for agriculture or other specific tasks, how public architecture or sacred places were shared by people from different residential groups or communities, how various resources such as springs, fields, or hunting grounds focused people's seasonal activities, and how all these along with contemporaneous residential sites were woven together by cultural or functional connections to make a complex whole that we can conceive of as a cultural landscape. This landscape may encompass large areas for certain periods and at other times it may be centered on particular communities. By thinking about heritage management at this level, we just might begin to stitch together a far more interesting and faithful picture of the past.

I offer a means to update and reconceive the contexts and the planning tools for the Basketmaker III and Pueblo I historic properties because I authored the 1999 context documents for these periods; and after having recently updated the research of the last two decades on these periods (Wilshusen 2018), I have concluded that we must transform how we think about heritage 
management in this region. The revision I offer here should be reasonably similar in concept to what would be required for the later Pueblo period sites in this area.

I must emphasize that this proposal needs to be thoroughly discussed and considered by archaeologists, SHPO, government land managers, tribal partners, and other key players in the Section 106 review process. The intent is to expand our review of the significance of properties and the potential of undertakings to affect historic properties to the level of the cultural landscape in certain cases. It would not deny or overturn the normal Section 106 review for individual properties, but simply place this review into the larger context of any potentially associated historic landscape. It would create a basic algorithm to emphasize the needs of current research and to promote mitigation decision-making focused on long-term heritage management.

For example, say there is a medium-sized federally funded undertaking that had the potential to affect several different historic properties ranging from a late Basketmaker-early Pueblo I residence to a small Pueblo III field house. Revised historic contexts would define the priorities for the various types of historic properties and eligible landscapes for each time period and offer a statistical weight for different types of eligible properties for each period. This would help decision-makers to identify the most valuable components for preservation or research. Possibly the later Pueblo agricultural field house and the potential remnants of a prehistoric field area might be judged more valuable for research or preservation on a particular landscape than a small early Pueblo residence, given the large sample of previously investigated residences and our relative lack of understanding about fields and field houses. This does not mean that the residential site would be discounted, just that the field house might have relatively more importance in the overall management and research design for the project. Whereas the residence might have limited investigations and appropriate monitoring for critical features or burials, the field house might be the focus of a long-term preservation plan along with any research necessary for planning.

My example above is only intended to show how presently under-valued resources may be seen in a new light when whole landscapes are added to our picture of the past. The basic argument here is that we need to set our goals on the long-term preservation of critically needed and endangered elements of the historic landscape. We need to frame our research to address questions about the broad sweep of human history in this area. Individual sites will remain the basic building blocks of our understanding of this history and key to any Section 106 evaluation, but we have to place these sites into context so that we build on what we already know and concentrate our future efforts on a mix of larger heritage needs and specific research goals. At present we do not have well-defined long-term preservation goals or up-to-date research plans for any context area. We have to consider that the whole historic context area is under threat of loss and to consider where we must increasingly concentrate our monies and other resources for preservation, for research, and for planning.

We must begin this effort soon if we are to have a meaningful sample universe of historic properties and landscapes in the near future. As human beings we are shaped by our landscapes and our cultures, as much as we shape them. The more we can understand the ways in which these landscapes and cultures have changed over time, the greater chance we will have of effectively managing current developments and ensuring a healthy and beautiful landscape in our future.

The Definition of the Context Area: The 1999 Context and Proposed Revisions

The 1999 Southern Colorado context was contained within state boundaries (figure 1), but the late Basketmaker-early Pueblo agricultural societies discussed in that volume were spread across southwestern Colorado, northwestern New Mexico, and southeastern Utah. This area is widely known among archaeologists as the greater Mesa Verde region or Northern San Juan region; it is critical that we place this history into this larger context if we are to appreciate key regional details and differences, as well as understand the broad sweep of historical change. Critical thematic elements ranging from ethnic heritage to differences in agriculture, settlement, and material culture vary across the region, but there is an overall historical unity to 


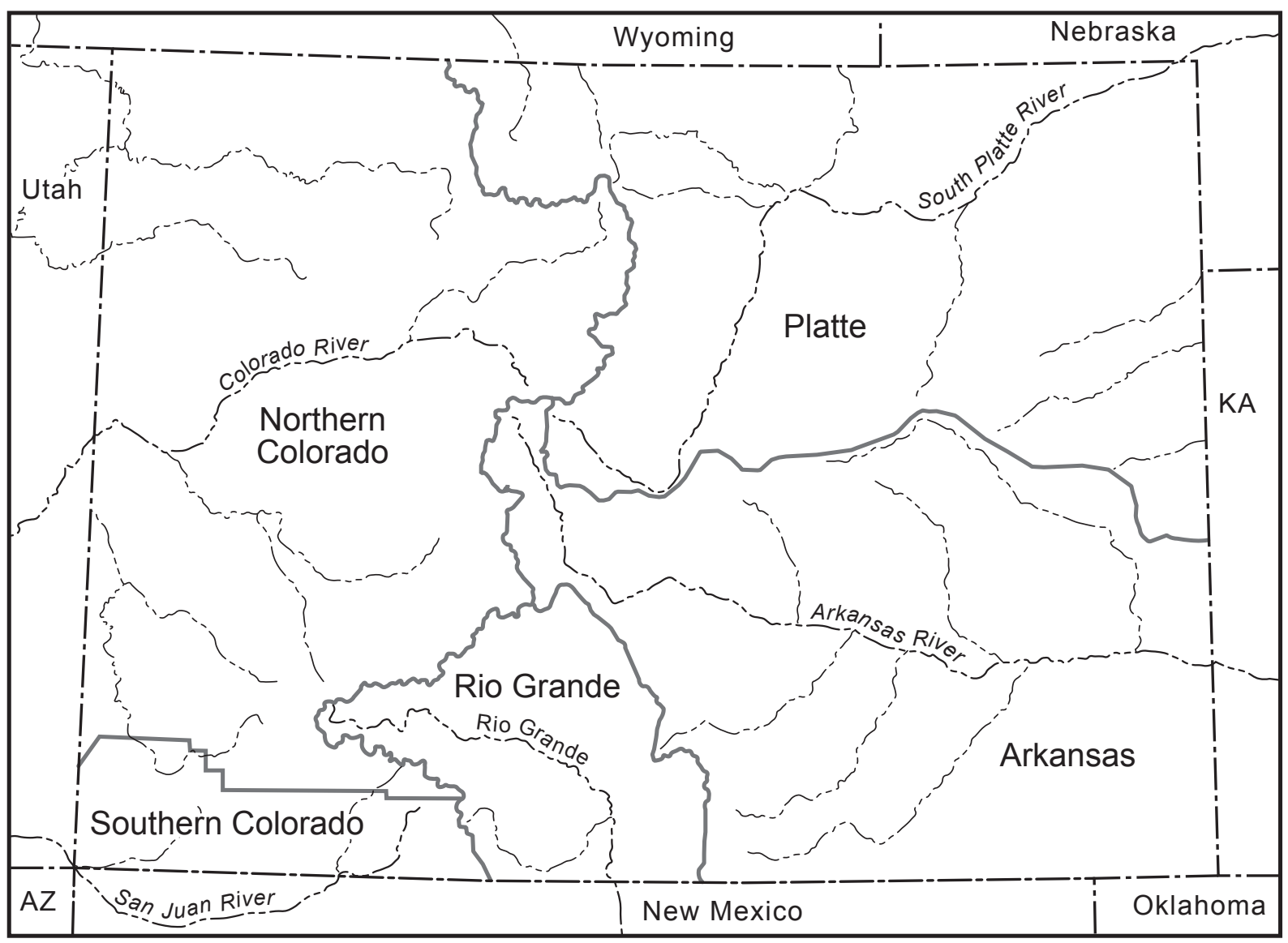

Figure 1. The river basin context areas as defined in 1999 (from Lipe 1999:2); the Southern Colorado is the focus of this article.

the region distinguishing it from surrounding areas between A.D. 600 and 1300 .

Beginning in the late Basketmaker period (A.D. 500-725) and certainly by the early Pueblo period (A.D. 725-920) the culture of this region emerges as a distinctive branch from others in the Southwest within the Ancestral Pueblotradition, with regionally distinctive ceramic styles, architectural designs, settlement patterns, and cultural landscapes. These four centuries establish the historic foundation for the Mesa Verde region, and the period's distinctive elements underlie its significance as a region with some of the earliest villages in the United States. Akin to the historic Santa Fe Trail, or the Shaker religious communities of New England, the historic context of the early Pueblo period for the Mesa Verde region defies the arbitrary confines of state boundaries. To understand the origins, fluorescence, and denouement of the cultural history of this period, especially with a focus on the significant themes and patterns that distinguish it, requires a change in how we define the context area.

The persistence of a distinctly Mesa Verde cultural identity-despite significant fluctuations in population size and periods of turbulence over many centuries-is something of interest in itself. Accordingly, it is important that our research and our preservation decision-making begin to recognize the full extent of this area. We must place at least some of our research and preservation efforts at this scale if we are ever to understand how the complex whole that we call the Mesa Verde region comes into being, persists for centuries through thick and thin, and yet at some point ends.

I propose that we expand the Southern Colorado River basin context area to conform to the greater Mesa Verde region if we are to truly understand its cultural landscapes (figure 2). This is an upland area well suited for dry land agriculture that is widely settled during the late Basketmaker-early Pueblo 
florescence. The division of the region into western, central, and eastern subregions is increasingly accepted (e.g., Glowacki 2015:Figure 3; Schachner et al. 2012) and is distinguished by historical developments and uses of the landscape specific to each subregion. Yet it is also clear in the late Basketmaker period that any boundaries between the subregions were fuzzy and porous.

Based on paleodemographic data there appear to have been significant population movements from one subregion to another at various times during the late Basketmaker-early Pueblo, and the cultural elements that help to differentiate one subregion from another are found in varying frequencies across the whole region. After A.D. 1040 the Central Mesa Verde region becomes even more expansive than portrayed in figure 2 , as the Chacoan regional system emerges. Over time the extent of Mesa Verde cultural influence encompasses much of the Northern San Juan region (Kohler and Varien 2012:Figure 1.1). There are alternate names (Upper and Lower San Juan regions) and slightly different eastern and western boundaries that have been proposed by Diederichs (2016:Figure 42) for the subregions in the late Basketmaker, and the terms we use can be debated, but whatever we call them the differences between the subdivisions, or subregions, appear to represent real cultural differences evident

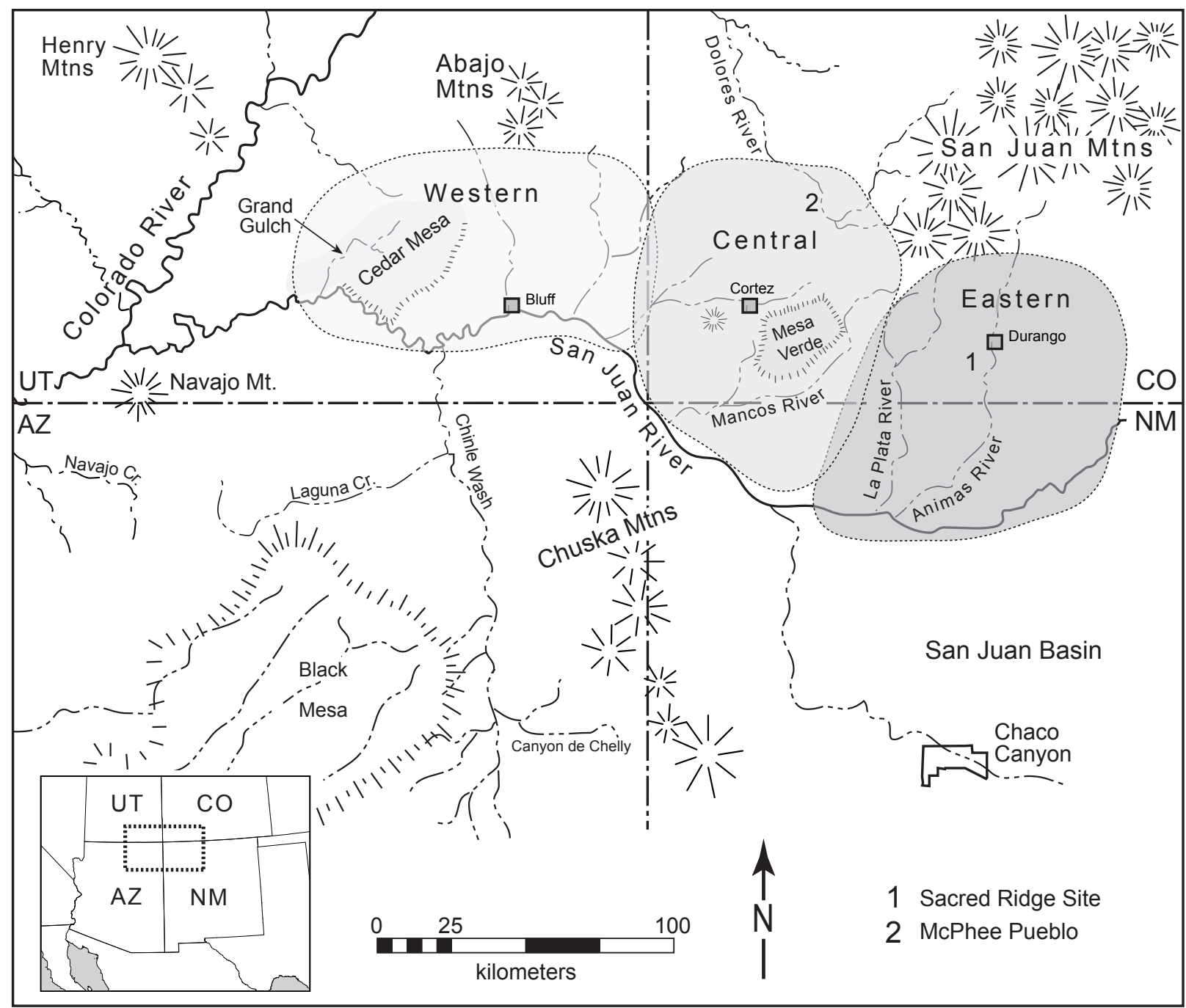

Figure 2. Expanded context area for the late Basketmaker-early Pueblo period in the Mesa Verde region, showing the three subregions, modern towns, and the general locations of two well-known early Pueblo sites, McPhee Pueblo and Sacred Ridge site. (Map produced by Phil Geib.) 
in ceramic types, perishable artifacts, architecture, settlement layout, and local histories.

There is no question why early farmers flooded into this region in the late Basketmaker period: it is incredibly rich farmland (figure 3 ). A fertile blanket of late Pleistocene loess-derived soils covering the area between 5,500 to $7,500 \mathrm{ft}$ (1,676 to $2,286 \mathrm{~m}$ ) in elevation and with an annual precipitation of 10 to 20 in $(25$ to $51 \mathrm{~cm})$ make this a fine setting for growing corn and beans. The expanded area covers slightly less than 28,000 square miles (approximately 74,000 $\mathrm{km}^{2}$ ) from the relatively arid setting of Comb Ridge, Utah in the west (figure 4) and stretches to the east to the forested edges of the San Juan Mountains in Colorado and the La Plata and Animas river valleys with their associated perched basins and Pleistocene river terraces (figure 5). It is bounded on the south by the high desert badlands between the San Juan River and the Mesa Verde cuesta and on the north by the high-altitude settings of the Abajo Mountains in Utah and the San Juan Mountains in Colorado. Besides the loess soils and sage plains found at the core of the region, there are also piñon-juniper and upland evergreen forests, rivers and springs, and large and medium-sized wild game that would have made this area attractive for early agriculturalists. It has just the right natural "ingredients" and landscape elements to host an integrated cultural landscape. For the Colorado context I suggest that the focus remain on the Central and Eastern Mesa Verde regions, but that the western area at least be acknowledged and discussed.
The Definition of the Context Area's Chronology: The 1999 Context and Proposed Revisions

In considering chronology I propose we replace the use of the terms "Basketmaker III" or "Pueblo I" periods, as defined under the Pecos chronology (Kidder 1927) as well as in the Southern Colorado River basin context, with the more broadly conceived late Basketmaker- early Pueblo period of the Mesa Verde region (A.D. 500-920). I do not doubt the very real differences in architecture and pottery between Basketmaker III and Pueblo $\mathrm{I}$, and it is clear that there is a dramatic decrease in tree-ring dated timbers (and possibly human habitations) across the region between A.D. 700 and 740 (Berry 1982; Bocinsky et al. 2016), but I still think that there may be real utility in looking at this as one period.

So why merge two periods that seem so clearly separable? It's because the changes of the early eighth century to the end of the ninth century (Pueblo I) sweep across the region unevenly and erratically. Changing social norms and uses of the landscape in one area of the region may be marked by relatively conservative behavior only 10 to 15 $\mathrm{km}$ away. Consequently, if we are to understand the fundamental social changes between A.D. 675 and 875, we cannot simply look before and after A.D. 725 or 750 . Some residential sites that date to the late eighth century look like Basketmaker III sites (e.g., Gooding 1980), and great kivas and dance circles, which some archaeologists would claim as

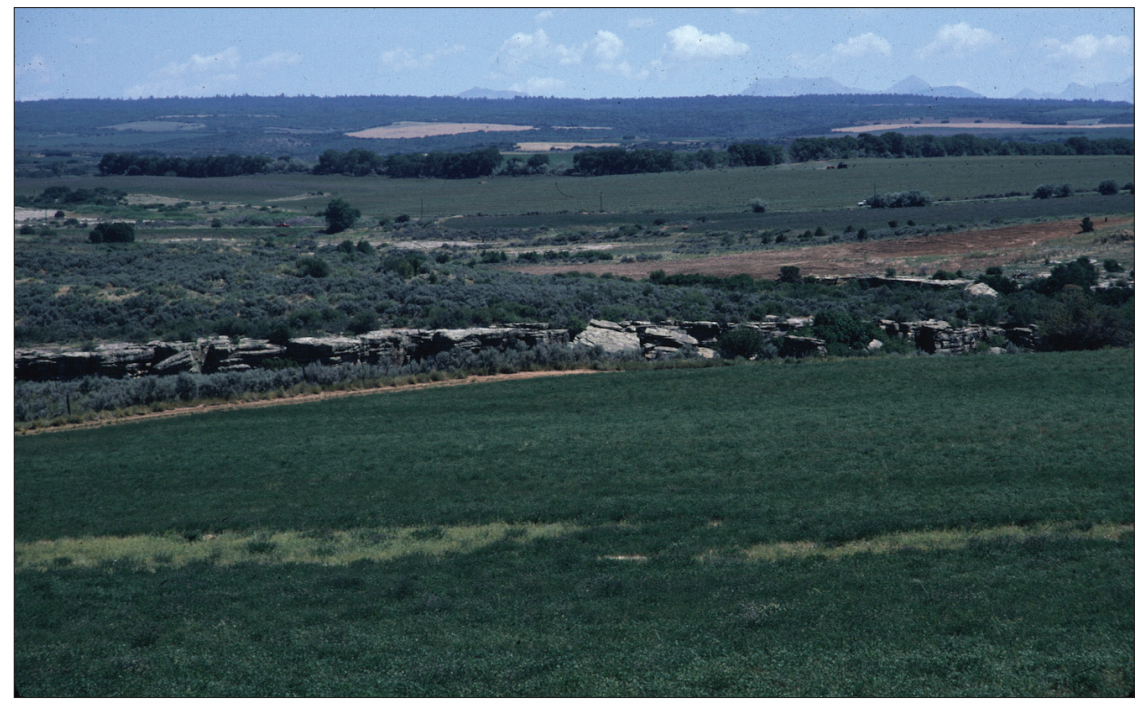

Figure 3. Central Mesa Verde farmlands with irrigated pasture in foreground, sage plain and dry-land bean fields in the background, looking west from the Yellow Jacket area. (Image SL-YJ-201 is reproduced by permission. Copyright University of Colorado Museum of Natural History.) 
Figure 4. Western Mesa Verde near Comb Ridge, Utah, looking approximately north. Author is marking the direction of $a$ Chaco-era "road" just to the west of Comb Ridge. (Image courtesy of Richard Wilshusen.)

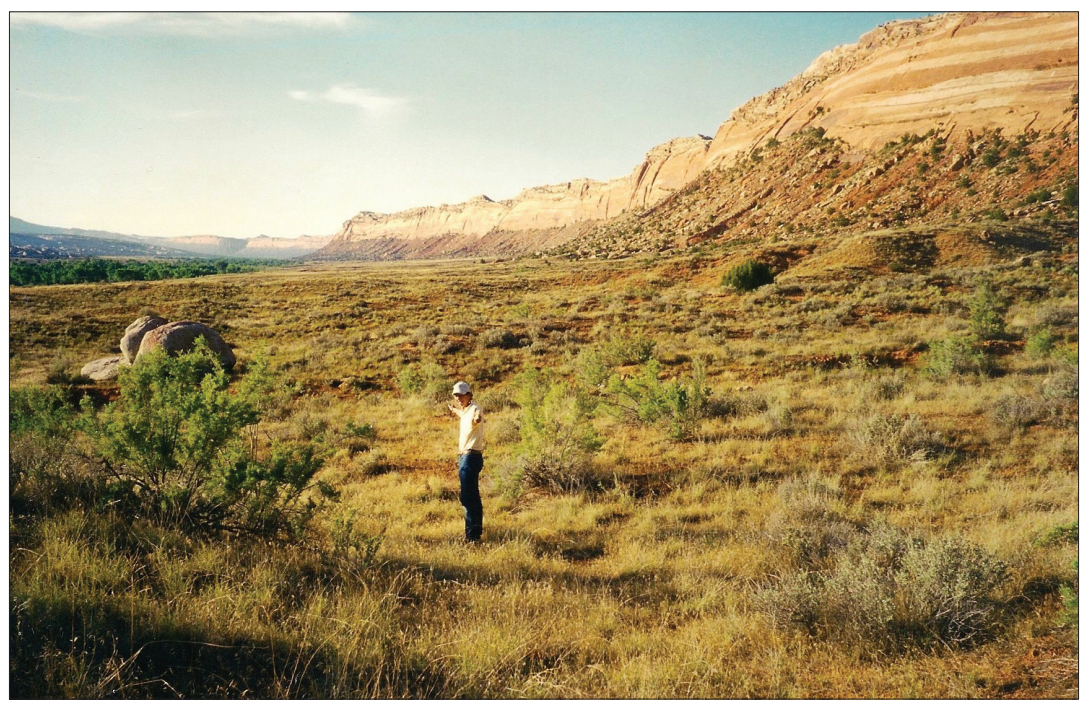

a marker of the Basketmaker III period, clearly are found throughout the region in the ninth century (Wilshusen 1999b).

I use the more general term of the late Basketmaker period here in order to disengage us from all the accumulated, and variable, notions of what started as the Basketmaker III stage in Kidder's 1927 Pecos Classification. Basketmaker III was defined as a sweeping, undated, stage of cultural development based on the discovery of a widely distributed pattern of cultural characteristics in the area drained by the San Juan River. This drainage basin is the same area where Kidder had previously defined three distinct cultural developments: Mesa Verde, Chaco, and Kayenta (Kidder 1924). The most basic features of this stage were the widespread adoption of pottery and increasing sedentism, as evidenced by the emergence of much more substantial residential architecture, storage facilities, and settlements than were common before. Ninety years after the debates of the first Pecos Conference we have largely forgotten the deeply debated issues that characterized the early research on the late Basketmaker-early Pueblo divide, as the early conceptions of widely shared, but poorly dated "stages" were replaced by more precisely dated periods such as Basketmaker III and Pueblo I.

Yet, problems remain within the Pecos Classification, given that the date ranges for any one period varied from one study area to another.

Figure 5. Eastern Mesa Verde in Ridges Basin, a perched basin just west of the Las Animas River near Durango. (Image courtesy of James Potter.)

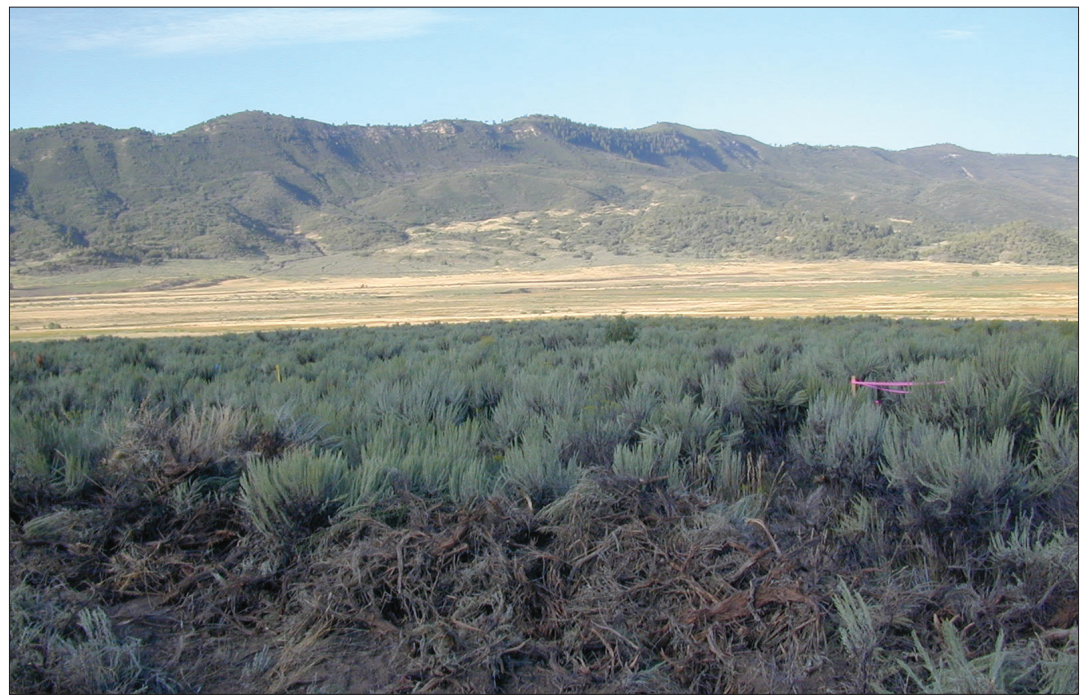


For example, a period such as Basketmaker III is variously dated as A.D. 400-700, 500-750, 500725 , or $500-700$, depending on which area of the northern Southwest one is studying and what references you cite. Our shared desire for a precisely dated period is reasonable, but a universally accurate and chronologically precise scheme is largely unobtainable because we now accept that there was far more large-scale population movement in the Southwest that was previously accepted. In addition, each area has its own ecological constraints and historical contingencies that create considerable temporal and material variability within a single period. Developments south of the San Juan River do not precisely match those to the north, and so forth.

By using a more generally encompassing term such as "late Basketmaker" it is possible to speak about changes over a wide landscape without tying them to any one locale or inferring more temporal precision than actually exists. For the purpose of this review and an earlier related article (Wilshusen 2018) I have chosen to use roughly A.D. 500-740 as the focus for my discussion of Basketmaker III in the Mesa Verde region. This is the period in which the commitment to farming lifeway spreads across this region and population increases at a rate far faster than ever seen before. A sedentary life style is manifest in substantial settlements and increasing household investment in large metates, multiple manos, large pottery vessels, storage rooms, and other substantial items and features.

In the same manner, the term "early Pueblo" period is used in place of the Pueblo I period to accommodate the variability in the dating of this period and related phase schemes elsewhere. Consequently, we do not need to debate whether the proper beginning for Pueblo I is A.D. 700, 725, 750, or 760; and we need not dispute if it ends at A.D. 900, 920, 925, or 950. Instead the early Pueblo period in the Mesa Verde region can be broadly conceived of as approximately A.D. 725 to 920 , which captures much of the disputed chronological territory, while still honoring the patterns we see in the immense regional tree-ring database we have for the late Basketmaker-early Pueblo period. My intent in using a more broadly conceived period scheme is to tap the descriptive power of the original Pecos stage scheme for characterizing broad cultural changes across an area and the chronometric accuracy of the period scheme, while not being unduly burdened with the baggage of differing conceptions of Basketmaker III and Pueblo I across the northern Southwest.

The main variation for early Pueblo from the old context chronology is the recognition that vestiges of the early Pueblo settlement system may persist until approximately A.D. 920. A significant decline in Mesa Verde population in the tenth century was already well recognized by 1999 (Lipe and Varien 1999; Wilshusen 1999b; Wilshusen and Ortman 1999) and this demographic shift with the abandonment of the large village settlements characteristic of early Pueblo developments in this region signals a shift that will ultimately lead to the florescence of the Chaco system to the south. Although additional evidence has somewhat tempered the magnitude of the drop in population (Wilshusen 1999b: 234 compared to Schwindt et al. 2016:Figure 3), the decline in population is still recognized as dramatic and clearly marks an end to the developments of this period. This significant decline in population lasted little more than a century, but few doubt that early Pueblo was a key turning point in the development of Southwestern, and especially Mesa Verdean, societies (Bocinsky et al. 2016; Kantner 2012; Wilshusen and Ortman 1999).

These changes should not hinder our ability to place sites within a distinct time frame (e.g., A.D. 650-725, or A.D 725-800) using the diagnostic temporal markers that readily characterize key material culture changes with which we are already familiar. Many of these changes are well cataloged or at least referenced in the earlier context (Wilshusen 1999a, 1999b), and a new context can focus on creating a more cohesive understanding of the importance of the broader landscape in future preservation, mitigation, and research efforts. By thinking of this as one general time period it should enhance our ability to model, portray, and even conserve elements of this early cultural and agricultural landscape.

The shift to a more general chronological scheme also may help us to span the increasing gap between the macrohistorical, transregional research efforts (Bocinsky et al. 2016; Mills et al. 2018) that utilize "big data" analyses and the "small data" research of 
day-to-day preservation work mandated by local, state, or federal regulations. The intent in moving to a broader chronological scheme and a regionally focused landscape approach is to help us transcend the state lines and ideological divides that have otherwise separated and weakened our research in the northern Southwest. We must combine the strengths of the small data with the ability to address the big questions of macrohistorical and transregional data syntheses.

\section{Key Themes for Future Work on the Early Pueblo Period in the Mesa Verde Region}

An update to the 1999 context must keep in mind the underlying principles of a historic context (NRHP 2002), as well as create a document that informs National Register eligibility decisions about late Basketmaker-early Pueblo archaeological sites in the future. Such a context should serve as "[a]n organizing structure for interpreting history that groups information about historic properties that share a common theme, common geographical area, and a common time period" (NRHP 2002:Glossary). Many archaeologists think of a context primarily as a research overview, given that archaeological sites often are evaluated on their merits for future research, but in this discussion I have emphasized the need to look at these historic resources within the framework of a historic landscape and its many heritage values (Lipe 2009), including but not exclusive to research.

How can we as archaeologists increasingly mix the triage work that we largely do under Section 106 of the NHPA with the heritage management issues of longer-range planning to better identify or predict where we are likely to find early Pueblo resources? How do we more quickly rank these resources in terms of our priority needs for preserving representative landscapes and even more important, how do we create regional plans for preservation? Contexts should aid us not only with identifying, evaluating, and registering properties, but also in assessing treatment and preservation options and heritage priorities. As mentioned earlier, there are some very promising initial significance modeling approaches that integrate multi-dimensional data to create adaptable, and yet accountable, historic preservation plans (Doelle et al. 2016; Heilen et al.
2016; Laurenzi et al. 2013; Sebastian 2009). We need to accelerate the testing, utilization, and refinement of these "outside-the-box" heritage management models by federal agencies and SHPO if we are to do more than triage.

To build upon the broad characterization of the trends and patterns as presented in the 1999 context and this update, I call attention to the most obvious historic themes that will aid us in understanding what is significant (and not so significant) about historic properties dating to this early agricultural period. We need to keep an eye on what is needed in the way of future inventory efforts, improvements or revisions in documentation efforts, research needs, and priorities for present and future protection and management. By making these themes clear and the significance of particular sites, districts, and landscapes more evident, we can anticipate improvements in everything from the various treatment options considered for different property types and landscapes affected by federal undertakings to enhanced long-term preservation planning to shield particular sites and landscapes, in order to ensure they are kept intact for future appreciation, education, and research.

Some of the most important themes presently evident in the late Basketmaker-early Pueblo period are highlighted in the following sections with short statements reemphasizing why they are crucial to the characterization of what makes this period important in state, national, and even international research on the Neolithic period. Almost all of the themes are evident in the discussion and citations mentioned previously as well as in Wilshusen (2018), so this is just a cursory treatment to serve as a summary of themes to be considered in a future context or in National Register nominations of sites or districts dating to this time period. Of course, any final acceptance of the proposed thematic elements would require appropriate consultation with and input from tribes and preservation partners.

\section{Agriculture}

As emphasized above the intensification of agriculture, increasing dependence on stored agriculturalgoods, and densely populatedlandscapes of this period are central to its distinctiveness. We only have the barest understanding of the way in 
which fields and field facilities might have been organized, and research on anthropogenic changes to the landscape and the effects of indigenous field clearing and farming methods (Adams 2004, 2006) is critical if we are to recognize ancient agricultural landscapes.

\section{Community Planning and Development}

Agricultural intensification and increasing sedentism certainly change the landscape and the locations, designs, and densities of communities. There is a period of relatively rapid population expansion and immigration to the area between A.D. 500 and 725/775, with the Central Mesa Verde region bridging the gap between the previously stark cultural differences seen to the east and west in earlier Basketmaker II occupations (Diederichs 2016). Between A.D. 775 and 875 the design of the aggregated communities goes through at least two and possibly three transformations with some of the final villages potentially having early great houses embedded in them (Wilshusen et al. 2012; Windes 2004, 2015). Although the vernacular architecture of this period is not as well appreciated as later building styles, few doubt the monumentality of great kivas and even some of the early great houses, and this civic architecture could show the work of master builders and designers.

\section{Economics}

The shift from a mixed agricultural and huntinggathering society to an economic system heavily dependent on agricultural goods and services totally transforms late Basketmaker and early Pueblo culture. This event is one of the defining features of the Neolithic revolution worldwide. The Animas-La Plata (ALP) research of the last decade suggests that different nearby communities had distinctive emphases in how their economies were organized and what products they yielded (Potter and Chuipka 2007). At the household level, there is increasing division in the labor of males and females, and aggregation in part may be due to new leadership strategies that better ensure economic success (Kantner 2012; Wilshusen and Perry 2012). It may be that the household economic models for dispersed settlements and for aggregated ones differ, and this could be key to better understanding how communities are organized and landscapes are altered. With the transformation of the loosely organized, dispersed communities of the seventh century into the tightly constructed village communities of the eighth and ninth centuries, is it possible that the more generalized sharing economies of dispersed communities may have been transformed to favor a more restricted reciprocal exchange system, with control of local resources in the hands of specific households or corporate groups (Bocinsky et al. 2016)?

\section{Ethnic Heritage}

The late Basketmaker-early Pueblo period is a turning point in the history of the current Pueblos. It may be the first time period in which we can begin to trace the origins of some of the current 21 federally recognized Pueblos and seven extant language groups (Ware 2014). At the time of the early Pueblo period there were likely no more than five ancestral languages, and many of the areas presently occupied by Pueblos were not densely settled. Migrations to the south and later divisions in groups help to explain the large number of historic pueblos and may help us to understand the origins of some of the historically spoken languages (e.g. Ortman 2012). However, to understand how the historic Pueblos came to share so much in common both genetically and culturally, while maintaining distinctly different languages, will necessitate a much larger approach than I can offer here (see Kohler 2013).

\section{Settlement of the Region}

The shift in settlement pattern from dispersed pithouse hamlets to aggregated pueblo villages is basic to the characterization of this period. This rapid shift is partly due to inherent population growth, but also is due to significant population influxes-primarily from the south and southwestand settlement of open agricultural territories by early farmers seeking new lands. Even when the highest percentage of the population is estimated to have been in villages, more than half of the population still lived in dispersed communities, so a rich research topic would be to better explain why 
some populations aggregate and others clearly do not. When villages disintegrate, do villagers simply return to a dispersed settlement pattern, or do they join another village? Immigration and settlement remain fertile research territory to be explored (Diederichs 2016).

Religion

Early Pueblo religious practice is evident in the construction design, floor features, and artifact remains found in key sodality or community architecture (Wilshusen, Ortman, and Phillips 2012). Some community structures appear to be oriented to have sight lines to key geographic features. Surviving shrines are rarely found outside of structures, but this may be as much due to a lack of recognition of these subtle features on survey rather than just to preservation issues. It is striking how many key features found in current Pueblo religious practices are already evident 1,200 years ago in these early Pueblo settings. Ritual practices are one of the key ways in which social identities and social memory are shaped and renewed, and over the last decades have been a rich topic for understanding social changes in this period (Geib et al. 2017; Van Dyke 2007).

\section{Creating a Heritage Management Plan: A Four- Step Process}

Archaeologists can learn a lesson from historic "main street" preservation projects of the last 50 years in thinking about how we might create a historic preservation plan for the Mesa Verde landscape. In the same way that our historic landscapes in the context area have been threatened by the rural developments of the last thirty years, the growth of suburbs and modern malls in the 1960s threatened to destroy traditional downtowns. In some cases, historic town centers and their buildings fell into disrepair; and in some big cities whole blocks of buildings were leveled by "urban renewal" projects, so as to leave the city without a center. Yet in other settings town planners experimented with turning the streets of historic downtowns into pedestrian malls or creating downtown historic preservation and renewal plans that focused cultural centers downtown. This renewal and a variety of incentives attracted small businesses, cafes, and the creative arts back to the city centers over the next generation.

Those historic main street revivals that succeeded had four basic ingredients. First, planners and preservation architects inventoried the stock of potentially historic buildings, parks, and other components that contributed to the city's identity. Once they knew the basic inventory, they then had to evaluate which elements or blocks of buildings were significant and predict which were worth saving in the short term, and which might need to be sacrificed or developed later. The creation of an initial preservation plan was derived from these first two steps and defined the priorities for renewing a block or several blocks of the old center of town. Through these initial experiments preservationists gained experience in how to rehabilitate significant properties, replace and in-fill those not worth saving, and to work with communities to create economically viable models to restore their city centers.

With this knowledge and a clear set of principles on how to balance preservation, renewal, and development for a particular town or city, it was possible to expand the vision of historic preservation and renewal to the larger urban landscape. As these efforts expanded from their original center, they adapted to new circumstances and opportunities, devising ways to create a "new" old downtown that remained consistent with the scale and feel-if not the exact style-of the original historic community center. This preserved, yet also enhanced the character and identity of the community by integrating new and modern facilities at the heart of a city, while rehabilitating many of the buildings that originally made that place attractive. Larimer Square in downtown Denver, Boulder's Pearl Street Mall, and Fort Collins's Old Town area all offer examples of how a preservation plan can expand to encompass a much larger area after beginning with a small portion of the original historic center of a town. The updated plans that followed were typically designed to incorporate new knowledge and new resources as this fourth on-going phase continually evolved. In many cases, the original center of the renewal experiment is now just a small part of a city that has been so revitalized that it is difficult to identify the original preservation elements. At that point the city has healed its old wounds and 
has a thriving commercial center at the heart of its community once again.

A version of these same four elements could be used to design and implement a region-wide heritage plan focused on the late Basketmakerearly Pueblo cultural landscape. The creation of an initial plan could be financed for a relatively modest amount of money if the right team was brought together. One of the key elements that would make such a plan realistic for the Mesa Verde region is the wealth of existing site data and relatively good survey coverage in many different locales across the region. This would facilitate the creation of an inventory database specifically designed to allow predictive modeling of the late Basketmaker-early Pueblo landscape.

This predictive modeling will only be outlined in general here, as it would be a key product to be created in the first stages of implementing a landscape-based heritage management program. It would have to encompass several different models, such as Bocinsky and Kohler's (2014) reconstruction of the annual rain-fed maize farming niche (the area where temperature and rainfall are sufficient to successfully grow maize in a specific year), a reconstruction of estimated population densities broken down by households per square kilometer in temporal increments as small as possible (Schwindt et al. 2016; Ortman et al. 2016), and frequency data for the types of sites that might be expected in any particular setting by temporal period (Ortman et al. 2007), and so forth. Essentially, the model would be predictive of where communities (e.g., Reese et al. 2019) and agricultural landscapes might be centered across the landscape at any particular time over the four-century period during which agriculture took hold.

\section{The First Two Elements: Assembling the Baseline Data and Predictive Modeling}

The initial inventory would need to focus on those attributes that will be most fundamental to creating the first approximation of a region-wide assessment of what remains of the prehistoric landscape. This appraisal will need to distinguish which portions of the landscape might still have integrity and which portions have been destroyed. We might be able to take a page from English
Heritage's Historic Landscape Characterisation program (Aldred and Fairclough 2003; Fairclough 2008) in our assessments of landscape definition, characterization, and integrity. By concentrating on those remaining areas with some integrity and reliable survey data, it should be possible to create a general model of settlement patterning and understand how land use changed through time. With luck we might be able to achieve a minimum resolution of at least 75-125 years (e.g., A.D. 600$725,725-800,800-875$, and so forth).

There are five periods and four fundamental changes in this four-century time span that might be possible to capture in any database: the dark period of incredibly low (or difficult-to-detect) population levels between A.D. 500 and 600; the initial immigration of farmers in the century thereafter (A.D. 600-675/700); the rapid growth of population and expansion of farming communities in the following 75-100 years (A.D. 675/700-775), which contributes to the eventual aggregation of up to half of the region's population into the earliest villages of 100 to more than 300 people between A.D. 775-875; and finally a period of increasing conflict, village disintegration, and large-scale emigration from many parts of the context area by A.D. 920. The intervals I suggest above are just suggestions, and as with all the details I offer here, are intended to initiate a dialogue. There may be only three or possibly five or more intervals that can be traced in these data, but the data will guide us as we seek an answer. I have no doubt it will be evident to those who undertake and complete this proposed inventory and assessment of the landscape.

Even in a very well surveyed area, such as the area covered by the Village Ecodynamics Project (VEP), with its well-documented occupation histories and chronologically diagnostic features and artifacts, archaeologists still have needed to utilize complex methods to create credible predictive models to estimate changes in settlement distribution, density, and composition through time (Ortman et al. 2007). In addition, models are only as good as the field observations they incorporate, and recent experiments comparing field observations with lab observations suggest that even very experienced crews have surprisingly limited capabilities in their field observations (Heilen and Altschul 2013). The challenges of fieldwork restrict the accuracy 
and precision of our classification of artifacts, description of soil types, and other common observations called for on site forms. Few of us like to admit it, but it is surprisingly difficult to replicate the detailed observations that we often make, and find, on site forms other than for the most basic data. Heilen and Altschul's research suggests that a more rudimentary set of site data, which would be replicable and reliable as observations, may be sufficient for most of our preservation and research needs.

Despite these caveats, when we aggregate the more than 40 years of professionally collected survey data from Section 106, Section 110, and privately commissioned inventories (e.g. Fetterman and Honeycutt 1994; Glowacki et al. 2012) with more 80 years' worth of excavation data, the result is the remarkably impressive predictive power evident in the results of the VEP (Kohler and Varien 2012; Schwindt et al. 2016) and the Basketmaker Communities Project (Ortman et al. 2016). By culling the least useful or least reliable information and normalizing or harmonizing the remaining information to improve data comparability, the resulting data sets can be surprisingly powerful for preservation planning, modeling population change and historical ecology, improving our dating methods, and similar tasks (e.g., Bureau of Land Management 2010; Kohler and Varien 2010; Varien et al. 2007).

All models inherently have some weaknesses and flaws, but even a rudimentary predictive model that helps us to identify settlement patterning changes through time or targeted research that improves our ability to classify previously recorded sites more accurately may be among the best tools for improving how we can make older site records more useful and reliable for current research and heritage management (Chuipka et al. 2010; Schlanger et al. 2015). What we seek over time are progressively more straightforward, even elegant, regional datasets that maximize the usefulness, durability, and accuracy of those site data that we can consistently expect to record (Wilshusen et al. 2016). But we have to start with what we have now, if we are to discover what data we can depend on to achieve more and more realistic models of past landscapes. As noted previously, these models should be made equally valuable for preservation planning, general research, and mitigation decisionmaking. If we build commonly shared platforms for data collection, analysis, and model building, everyone should benefit.

These first two steps will take time, but if successful they will inform a later discussion of how to create a framework to prioritize resources based on their particular values at the landscape level and their potential to contribute to our various heritage management needs. They might also lead to prioritizing protection or acquisition of certain elements of the landscape that we presently do not recognize as valuable heritage assets (Lipe 1974).

\section{The Last Two Elements: Setting Priorities and Drafting a Context}

The most important task for any predictive or data refinement work at this initial stage is to help archaeologists, planners, and other concerned parties begin to create a long-term preservation priority list of sites and locales in this region. We do not like to admit it, but most of us have unspoken ways that we rank significant sites for research and preservation; as archaeologists who work in resource management we regularly make or implement decisions relative to the perceived value of different cultural resources (Mitchell 2018). Although we can recognize that structural sites and not-structural sites can equally have sufficient integrity and significance to be evaluated as historic properties, we still may have a tendency to protect or to target research at the structural site more often than at the non-structural site. By tying our priorities to the information obtained from our initial predictive modeling we can make our system for evaluating resources more explicit and open to examination and revision so that all eligible sites and elements of the landscape get equal consideration, based on our preservation and research needs.

A recent approach used for cultural resources planning in southern Arizona (Laurenzi et al. 2013) offers an example of how we might begin to prioritize our heritage planning and preservation in particular locales. The strategy used in Arizona combines existing archaeological survey data, predictive locational models, and expert opinionsboth professional and avocational-in designing regional preservation priorities. When these sources 
of information were merged and land ownership and current-day land use were considered, it was possible to rank areas for their overall potential value for long-term preservation, active research, education or enjoyment, or a combination of values (Lipe 2009). This priority-driven preservation plan was then used to help with research, mitigation, and preservation decision-making so that critical landscape resources were given due consideration.

To create a region-wide priority model we might apply the basic principles sketched here to an already well-developed study area within the region, such as the VEP research area. This study encompasses $4,569 \mathrm{~km}^{2}$ in the Central Mesa Verde region and has a dataset of approximately 18,000 documented sites. Although this study area represents about six percent of the greater Mesa Verde region, it is almost in the center of the region and offers a wide range of settings and sites that would offer a good test case of how to create an initial set of long-term heritage management priorities to balance both research and preservation for the region.

Even a rudimentary decision-making paradigm that incorporated information such as landownership status and preservation priorities for different locales comprising the landscape, along with recommendations for future needs, could noticeably improve our heritage management decisions over the long term. Such a paradigm would be of aid in evaluating research needs, mitigation options, and acquisition priorities, as well as knowing where to engage volunteers in site stewardship and additional survey work. This also would help to prioritize the granting of preservation monies and making other typical conservation decisions. This simplified model certainly would need to be regularly evaluated in its first years to make sure it satisfied NHPA requirements as it was implemented, but it should not be too difficult to design a plan permitting both quantitative and qualitative assessment of its strengths and weaknesses.

\section{A New Breed of Historic Context}

In the end, possibly two to five years after the beginning of this process, we should be able to draft a new landscape-focused context and heritage plan for the late Basketmaker-early Pueblo cultural resources of this region, and possibly have contexts and plans for the other major periods as well. Any approved context document would exist as a living digital document with accompanying data sets accessible to professionals and permitted avocational researchers. New information would be incorporated as it became available and, most importantly, the plan would lay out the most critical goals and rationale for research and preservation for the next five to ten years, with the means to measure progress or setbacks for each goal on a regular basis.

As mentioned, I think archaeologists can learn a lesson from the revitalization of historic main streets and downtowns that have combined the long-term conservation and integration of key elements of the historic fabric of their cities and towns with the economic and social revitalization of their communities. As archaeologists, heritage managers, and public planners, we have comparable opportunities to conserve key elements of our cultural landscapes while facilitating thoughtful planning efforts regarding future water needs, economic development, public roads, and other developments that advance the common good of a community.

This could begin as a pilot project to better understand how to write statewide guidance for historic preservation projects and programs. Towns as diverse as Georgetown, Fort Collins, Denver, Cortez, Pueblo, Salida, Crested Butte, and Durango have seen their historic downtowns renewed and their local communities prosper with town planning that unites historic preservation with other community economic and social needs. In the same way, we can begin to understand how to preserve elements of our historic landscapes while combining this with the resurgence of our smaller communities as more and more people move to Colorado.

This course of action would require a totally new and different sort of historic context, a context that would encourage us to balance long-term preservation and research goals. Planning in this manner also offers support for decision-making regarding the inevitable sacrifices that must be made as landscapes are developed. By making preservation planning increasingly proactive, rather than just reactive, we just might have a chance of having a historic landscape that benefits all of us 
ten to forty years from now. And I bet we also will transform our understanding of the past in a way that allows us to see these landscapes anew.

A historic context and associated heritage plan would be the fourth and final element; they would bring together and synthesize what had been learned from testing and refining the first three elements of the plan over a two-to-five-year period. The context would frame what is known about the sites, cultural landscapes, and history of the region and likely create a simplified site type list and a somewhat simplified site form (in collaboration with SHPO) focused on those site variables most critical for research and preservation, yet variables that can be regularly and consistently be recorded in an archaeological survey. The context would also create the means to evaluate the sufficiency of the site data and the resulting predictive models at the core of the mitigation decision-making paradigms, so that improvements could be made based on annual, as well as cumulative five-year, reviews. In general, the context would outline a preservation plan and broad mitigation objectives for the next five to ten years.

\section{In Sum: Expanding Our Preservation Perspective and the Need for a New Context}

A larger scale of planning will necessitate that we evaluate the accuracy, durability, and usability of our current regional survey data (Wilshusen et al. 2016). We must do this if we are to begin to build a first approximation model of past cultural landscapes. We have to be able to distill what we presently know about the past landscape if we are to decide what our heritage management priorities should be as we make land use decisions today and tomorrow. These priorities will be critical for creating guidelines to help us make day-to-day judgments about what to preserve and what to cede in the future (Doelle et al. 2016). By more clearly defining our values and our priorities we also will have to acknowledge the diversity of our long-term preservation needs, ranging from education to research to even the sacredness of certain claims (Colwell and Ferguson 2014).

Although my original intent in writing a review of the state of late Basketmaker-early Pueblo archaeological research was simply to update aspects of the 1999 context (Wilshusen 2018), as I delved into the topic I realized that we are at a turning point that may require a totally new kind of context. It should meld an up-to-date research summary with generally agreed upon site values and preservation priorities to create a regional preservation plan and an entirely new context for the early agricultural and cultural landscape of the late Basketmaker-early Pueblo period. This plan would have measurable goals associated with it, have a regular schedule for evaluation and revision (as needed), and should also serve to inform our dayto-day decision-making on mitigation, research, and preservation.

The expansion I have proposed sounds complicated, and some aspects of it-after discussion and debate-may be improved if somewhat simplified. However, based on my experience with the 1999 context I actually think this plan is quite feasible. When those contexts were first seriously considered at a Colorado Council of Professional Archaeologists meeting focused on their design and implementation, many thought them to be overly ambitious, a bit of boondoggle, and an administrative nightmare that would not see timely completion. Yet, through careful oversight by an overall coordinator and awarding grants to proven teams of collaborators it was possible for five different teams to produce exemplary volumes that have proven surprisingly useful and been widely cited over the last two decades (Mitchell 2018).

By focusing on a particular temporal element of the Pueblo past and a region that has received a tremendous amount of recent synthetic research, certain aspects of this proposal should be easier to address in the Mesa Verde region than elsewhere in the state. By discussing and ultimately agreeing upon general priorities for preservation and research focused on this context topic, we should actually lay a path for priority decision-making on later Pueblo periods, which would all together be a huge gain. It would result in a plan for region-wide preservation and research with a reasonable amount of accountability and could transform how we think about early Pueblo agricultural communities and how we make sense of them to a wider public. 


\section{Concluding Remarks}

It is critical that we find ways to regularly update our historic contexts to make them more usable, accessible, and data-rich. I have suggested a comprehensive new kind of context and heritage plan that incorporates both research and historic preservation goals and objectives. Three initial steps-the creation of an active site database for the context area, development of a predictive model that is focused at the landscape level, and the prioritization of preservation and research goals for these early Pueblo agricultural and cultural landscapes-would precede what would be a new context that could guide both short-term mitigation measures and our long-term preservation and research goals. If we can begin to recognize communities and their associated agricultural landscapes across the region, we should to be able to make significant progress in better understanding many of the most important issues associated with this period.

The emphasis here has been on late Basketmakerearly Pueblo landscapes because of their rapid loss to development associated with new retirement homes, irrigated fields, and growth in the energy industry. Crow Canyon Archaeological Center and the VEP have produced excellent reference material on the later Pueblo occupations in the Mesa Verde region and these likely could readily inform and help to expedite some of the planning process I have suggested earlier. If the late Basketmaker-early Pueblo context proves to be valuable at creating a longer-term vision for researching and preserving sites and landscapes of this period when compared to our current practice, then it may provide a model for creating similar contexts for the later Pueblo periods dating between A.D. 920 and 1300 .

Acknowledgements. The suggestions of two anonymous reviewers to an original manuscript totally reoriented both this manuscript and an earlier review I published in 2018. Critical remarks and final reviews by Tim Kohler, Mark Mitchell, Holly Norton, Mark Tobias, and Michael Heilen markedly improved the revised manuscript. In a few cases I actually borrowed language they suggested in their recommendations for my revision, but I must emphasize that I alone am responsible for the text and the proposal offered here.

\section{References Cited}

Adams, Karen R.

2004 Anthropogenic Ecology of the North American Southwest. In People and Plants in Ancient Western North America, edited by Paul E. Minnis, pp. 167-204. Smithsonian Books, Washington, D.C.

2006 Through the Looking Glass: The Environment of the Ancient Mesa Verdeans. In The Mesa Verde World: Explorations in Ancestral Pueblo Archaeology, edited by David Grant Noble, pp. 1-8. School of American Research Press, Santa Fe.

Aldred, Oscar, and Graham Fairclough

2003 Historic Landscape Characterisation: Taking Stock of the Method. English Heritage, London. Electronic document, http://archaeologydataservice. ac.uk/archiveDS/archiveDownload? $\mathrm{t}=$ arch-1583-1/ dissemination/pdf/HLCTakingStock.pdf. Accessed December 24, 2018.

Anderson, David G., Thaddeus G. Bissett, Stephen J. Yerka, Joshua J. Wells, Eric C. Kansa, Sarah W. Kansa, Kelsey Noack Myers, R. Carl DeMuth and Devin A. White

2017 Sea-Level Rise and Archaeological Site Destruction: An Example from the South-Eastern United States Using DINAA. PLOS One 12(11): e0188142. https://doi. org/10.1371/journal.pone.0188142

Anschuetz, Kurt F., Cherie L. Scheick, Steven R. Mack,

Wetherbee B. Dorshow, and Timothy R. Baugh

1999 A Regional Approach to the Cultural Landscapes of Northeast New Mexico: A Research Design for the Ration Properties: Nahk'eyaa: Our Footprints Are There. Southwest Archaeological Consultants Research Series 425a, Southwest Archaeological Consultants, Santa Fe. Bender, Susan J.

2011 Nomination of the Threemile Gulch Prehistoric Archaeological District, Site 5PA4455, to the National Register of Historic Places. National Park Service, U.S. Department of the Interior, Washington, D.C. Listed on the National Register, September 13, 2011.

Berry, Michael S.

1982 Time, Space, and Transition in Anasazi Prehistory. University of Utah Press, Salt Lake City.

Bocinsky, R. Kyle, and Timothy A. Kohler

2014 A 2,000-Year Reconstruction of the Rain-fed Maize Agricultural Niche in the US Southwest. Nature Communications 5: Article Number 5618. https://doi. org/10.1038/ncomms6618.

Bocinsky, R. Kyle, Johnathan Rush, Keith W. Kintigh, and Timothy A. Kohler

2016 Exploration and Exploitation in the Macrohistory of the Pre-Hispanic Pueblo Southwest. Science Advances 2(4) e1501532. https://doi.org/10.1126/sciadv.1501532

Bureau of Land Management

2010 Canyons of the Ancients National Monument Record of Decision and Resource Management Plan. Electronic document, https://eplanning.blm.gov/eplfront-office/projects/lup/65701/79872/92628/CANM ARMP ROD.pdf. Accessed December 2010.

Chuipka, Jason, Richard H. Wilshusen, and Jerry Fetterman

2010 The Northern San Juan Basin Settlement and 
Survey Project, Archuleta and La Plata Counties, Colorado. Woods Canyon Archaeological Consultants, Yellow Jacket, Colorado. Report submitted to the San Juan Resource Center, Durango.

Colwell, Chip and T.J. Ferguson

2014 The Snow-Capped Mountain and the Uranium Mine: Zuni Heritage and the Landscape Scale in Cultural Resource Management. Advances in Archaeological Practice 2(4):234-251. https://doi.org/10.7183/23263768.2.4.234

Diederichs, Shanna R.

2016 Basketmaker III Colonization and the San Juan Frontier. Unpublished M.A. thesis, Department of Anthropology, Northern Arizona University, Flagstaff.

Doelle, William H., Pat Barker, David Cushman, Michael Heilen, Cynthia Herhahn, Christina Rieth

2016 Incorporating Archaeological Resources in Landscape-Level Planning and Management. Advances in Archaeological Practice 4(2):118-131. https://doi. org/10.7183/2326-3768.4.2.118

Fairclough, Graham J.

2008 A New Landscape for Cultural Heritage Management: Characterisation as a Management Tool. In Landscapes Under Pressure: Theory and Practice of Cultural Heritage Research and Preservation, edited by Ludomir R. Lozny, pp. 55-74. Springer, Boston.

Fetterman, Jerry, and Linda Honeycutt

1994 Interim Report on the Archaeological Survey of Indian Camp Ranch, Southwestern Colorado. Indian Camp Ranch Report 3. Woods Canyon Archaeological Consultants, Inc., Yellow Jacket, Colorado.

Geib, Phil R., Carrie Heitman, and Ronald C.D. Fields

2017 Continuity and Change in Puebloan Ritual Practice: 3,800 Years of Shrine Use in the North American Southwest. Anthropology Faculty Publications 137. Electronic document, http://digitalcommons.unl.edu/ anthropologyfacpub/137. Accessed November 2018.

Glowacki, Donna M.

2015 Living and Leaving: A Social History of Regional Depopulation in Thirteenth-Century Mesa Verde. University of Arizona Press, Tucson.https://doi.org/ $\underline{10.2307 / j . c t t 183 p d d h}$

Glowacki, Donna M., with Elise Alonzi, Kyle Bocinsky, and Kelsey Reese

2012 The Mesa Verde Community Center Survey: Documenting Large Pueblo Villages in Mesa Verde National Park. Unpublished manuscript, Mesa Verde National Park, Mancos, Colorado, and Department of Anthropology, Washington State University, Pullman.

Gooding, John

1980 The Durango South Project: Archaeological Salvage of Two Late Basketmaker III Sites in the Durango District. Anthropological Papers 34. University of Arizona Press, Tucson.

Hardesty, Donald L.

2010 Mining Archaeology in the American West: A View from the Silver State. University of Nebraska Press, Lincoln.

Heilen, Michael, and Jeffrey H. Altschul

2013 The Accuracy and Adequacy of In-Field Artifact
Analysis: An Experimental Test at Two Archaeological Sites in the Western United States. Advances in Archaeological Practice 1(2):121-138. https://doi. org/10.7183/2326-3768.1.2.121

Heilen, Michael, Jeffrey H. Altschul, Seetha Reddy, Robert Heckman, and Stephen Norris

2016 Locational and Significance Modeling at San Clemente Island, California. Technical Report 15-58. Statistical Research, Redlands, California.

Heilen, Michael, Jeffrey H. Altschul, and Fredrich Lüth

2018 Modelling Resource Values and Climate Change Impacts to Set Preservation and Research Priorities. Conservation and Management of Archaeological Sites 20(4):261-284. https://doi.org/ $10.1080 / 13505033.2018 .1545204$

History Colorado

2011 The Power of Heritage and Place: A 2020 Action Plan to Advance Historic Preservation in Colorado. History Colorado, Denver.

Kantner, John

2012 The Early Pueblo Period: A Synthesis of Sorts. In Crucible of Pueblos: The Early Pueblo Period in the Northern Southwest, edited by Richard H. Wilshusen, Gregson Schachner, and James R. Allison, pp. 223-233. Cotsen Institute of Archaeology Press, University of California, Los Angeles.

Kidder, Alfred V.

1924 An Introduction to the Study of Southwestern Archaeology, with a Preliminary Account of the Excavations at Pecos. Phillips Academy, Andover, Massachusetts.

1927 Southwestern Archaeological Conference. Science 66: 489-91.

Kohler, Timothy A.

2013 How the Pueblos Got Their Sprachbund. Journal of Archaeological Method and Theory 20(2): 212-234. https://doi.org/10.1007/s10816-012-9145-4

Kohler, Timothy A. and Mark D. Varien

2010 A Scale Model of Seven Hundred Years of Farming Settlements in Southwestern Colorado. In Becoming Villagers: Comparing Early Village Societies, edited by Matthew S. Bandy and Jake R. Fox, pp. 37-61. University of Arizona Press, Tucson.

Kohler, Timothy A. and Mark D. Varien (editors)

2012 Emergence and Collapse of Early Villages: Models of Central Mesa Verde Archaeology. University of California Press, Berkeley and Los Angeles.

Laurenzi, Andy, Matthew A. Peeples, William H. Doelle

2013 Cultural Resources Priority Area Planning in Sub-Mogollon Arizona and New Mexico. Advances in Archaeological Practice 1(2):61-76. https://doi. org/10.7183/2326-3768.1.2.61

Lipe, William D.

1974 A Conservation Model for American Archaeology. Kiva 39(3-4):213-245.

1996 Cannonball Ruins (5MT338). National Register of Historic Places Registration Form, submitted by Crow Canyon Archaeological Center, Cortez, Colorado. State Historic Preservation Office, Colorado Historical Society, Denver. Listed on the National Register, April 
30, 1997.

1999 Introduction. In Colorado Prehistory: A Context for the Southern Colorado River Basin, edited by William D. Lipe, Mark D. Varien, and Richard H. Wilshusen, pp. 1-13. Colorado Council of Professional Archaeologists, Denver.

2009 Archaeological Values and Resource Management. In Archaeology and Cultural Resource Management: Visions for the Future, edited by Lynne Sebastian and William D. Lipe, pp. 41-63. School for Advanced Research, Santa Fe.

Lipe, William D. and Mark D. Varien

1999 Pueblo II (A.D. 900-1150). In Colorado Prehistory:

A Context for the Southern Colorado River Basin, edited

by William D. Lipe, Mark D. Varien, and Richard

H. Wilshusen, pp. 242-289. Colorado Council of Professional Archaeologists, Denver.

Lipe, William D., Mark D. Varien, and Richard H. Wilshusen (editors)

1999 Colorado Prehistory: A Context for the Southern Colorado River Basin. Colorado Council of Professional Archaeologists, Denver.

Mills, Barbara J., Matthew A. Peeples, Leslie D. Aragon, Benjamin A. Bellorado, Jeffrey J. Clark, Evan Giomi, and Thomas C. Windes

2018 Evaluating Chaco Migration Scenarios Using Dynamic Social Network Analysis. Antiquity 92(384): 922-939. https://doi.org/10.15184/aqy.2018.86

Mitchell, Mark D.

2018 Introducing Reviews in Colorado Archaeology, a New Online Journal of Archaeological Research and Cultural Resources Management. Reviews in Colorado Archaeology 1(Article 1):1-9.

National Register of Historic Places (NRHP)

1991 How to Apply the National Register Criteria for Evaluation. National Register Bulletin 15. U.S. Department of the Interior, National Park Service, Interagency Resources Division, Washington, D.C.

2002 How to Apply the National Register Criteria for Evaluation. Internet revision. National Register Bulletin 15. U.S. Department of the Interior, National Park Service, Interagency Resources Division, Washington, D.C.

Ortman, Scott G.

2012 Winds from the North: Tewa Origins and Historical Anthropology. University of Utah Press, Salt Lake City.

Ortman, Scott G., Shanna Diederichs, Kari Schleher, Jerry

Fetterman, Marcus Espinosa, and Caitlin Sommer

2016 Demographic and Social Dimensions of the Neolithic Revolution in Southwest Colorado. Kiva 82(3):232-258. https://doi.org/10.1080/00231940.2016. $\underline{1214055}$

Ortman, Scott G., Mark D. Varien, and Lee Gripp

2007 Empirical Bayesian Methods for Archaeological Survey Data: An Application from the Mesa Verde Region. American Antiquity 72:241-272. https://doi. org/ 10.2307/40035813

Potter, James M., and Jason P. Chuipka

2007 Early Pueblo Communities and Cultural Diversityin the Durango Area: Preliminary Results from the Animas-La Plata Project. Kiva 72:407-430. https://doi.org/10.1179/kiv.2007.72.4.002

Reese, Kelsey M., Donna M. Glowacki, and Tim Kohler

2019 Dynamic Communities on the Mesa Verde Cuesta. American Antiquity 1-20. https://doi.org/10.1017/ aaq.2019.74.

Schachner, Gregson, Kellam Throgmorton, Richard H. Wilshusen, and James R. Allison

2012 Early Pueblos in the American Southwest: The Loss of Innocence and the Origins of the Early Southwestern Village. In Crucible of Pueblos: The Early Pueblo Period in the Northern Southwest, edited by Richard $\mathrm{H}$. Wilshusen, Gregson Schachner, and James R. Allison, pp. 1-13. Cotsen Institute of Archaeology, University of California, Los Angeles.

Schlanger, Sarah, Richard H. Wilshusen, and Heidi Roberts

2015 From Mining Sites to Mining Data: Archaeology's Future. Kiva 81 (1-2): 80-99. https://doi.org/10.1080/00 231940.2015.1118739

Schwindt, Dylan M., R. Kyle Bocinsky, Scott G. Ortman, Donna M. Glowacki, Mark D. Varien, and Timothy A. Kohler

2016 Social Consequences of Climate Change in the Northern Southwest. American Antiquity 81(1):74-96. https://doi.org/10.7183/0002-7316.81.1.74

Sebastian, Lynne

2009 Deciding What Matters: Archaeology, Eligibility, and Significance. In Archaeological \& Cultural Resource Management: Visions for the Future, edited by Lynne Sebastian and William D. Lipe, pp. 91-114. School for Advanced Research Press, Santa Fe, New Mexico.

Van Dyke, Ruth M.

2007 The Chaco Experience: Landscape and Ideology at the Center Place. School for Advanced Research Press, Santa Fe.

Varien, Mark D., and Shanna R. Diederichs

2012 Nomination of the Indian Camp Ranch Archaeological District, Site 5MT19927, to the National Register of Historic Places. Accepted and listed on the National Register of Historic Places, National Park Service, Washington, D.C.

Varien, Mark D., Scott G. Ortman, Timothy A. Kohler, Donna M. Glowacki, and C. David Johnson

2007 Historical Ecology in the Mesa Verde Region: Results from the Village EcoDynamics Project. American Antiquity 72:273-300. https://doi. org/10.2307/40035814

Ware, John A.

2014 A Pueblo Social History: Kinship, Sodality, and Community in the Northern Southwest. School for Advanced Research Press, Santa Fe.

Whittlesey, Stephanie M.

1997 Archaeological Landscapes: A Methodological and Theoretical Discussion. In Vanishing River: Landscapes and Lives of the Lower Verde Valley-The Lower Verde Valley Archaeological Project: Overview, Synthesis, and Conclusions, edited by Stephanie M. Whittlesey, Richard Ciolek-Torrello, and Jeffrey H. Altschul, pp. 17-28. SRI Press, Tucson, Arizona.

Wilshusen, Richard $\mathrm{H}$.

1999a Basketmaker III (A.D. 600-750). In Colorado 
Prehistory: A Context for the Southern Colorado River Basin, edited by William D. Lipe, Mark D. Varien, and Richard H. Wilshusen, pp. 166-195. Colorado Council of Professional Archaeologists, Denver.

1999b Pueblo I (A.D. 750-900). In Colorado Prehistory: A Context for the Southern Colorado River Basin, edited by William D. Lipe, Mark D. Varien, and Richard H. Wilshusen, pp. 196-241. Colorado Council of Professional Archaeologists, Denver.

2018 How Agriculture Took Hold in the Mesa Verde Region: A Review of Recent Research on the Late Basketmaker - Early Pueblo Periods (A.D. 500-920). Reviews in Colorado Archaeology 1(Article 4):69-95. https://doi.org/10.32946/RCA.2018.0004

Wilshusen, Richard H., Michael Heilen, Wade Catts, Karyn de Dufour, and Brad Jones

2016 Archaeological Survey Data Quality, Durability, and Use: Findings and Recommendations. Advances in Archaeological Practice 4(2):106-117. https://doi. org/10.7183/2326-3768.4.2.106

Wilshusen, Richard H. and Scott G. Ortman

1999 Rethinking the Pueblo I Period in the Northern Southwest: Aggregation, Migration, and Cultural Diversity. Kiva 64:369-399. https://doi.org/10.1080/002 31940.1999.11758389

Wilshusen, Richard H., Scott G. Ortman, Shanna Diederichs, Donna M. Glowacki, and Grant Coffey

2012 Heartland of the Early Pueblos: The Central Mesa Verde. In Crucible of Pueblos: The Early Pueblo Period in the Northern Southwest, edited by Richard H. Wilshusen, Gregson Schachner, and James R. Allison, pp. 14-34. Cotsen Institute of Archaeology, University of California, Los Angeles.

Wilshusen, Richard H., Scott G. Ortman, and Ann Phillips

2012 Processions, Leaders, and Gathering Places: Changes in Early Pueblo Community Organization as Seen in Architecture, Rock Art, and Language. In Crucible of Pueblos: The Early Pueblo Period in the Northern Southwest, edited by Richard H. Wilshusen, Gregson Schachner, and James R. Allison, pp. 198218. Cotsen Institute of Archaeology, University of California, Los Angeles.
Wilshusen, Richard H. and Elizabeth Perry

2012 Women's Central Role in Early Pueblo Change: Ground Stone, Archaeobotanical, Ceramic, Architectural, and Skeletal Evidence. In Crucible of Pueblos: The Early Pueblo Period in the Northern Southwest, edited by Richard H. Wilshusen, Gregson Schachner, and James R. Allison, pp. 185-197. Cotsen Institute of Archaeology, University of California, Los Angeles.

Windes, Thomas C.

2004 The Rise of Early Chacoan Great Houses. In In Search of Chaco: New Approaches to an Archaeological Enigma, edited by David Grant Noble, pp. 14-21. School of American Research, Santa Fe.

2015 Early Greathouse Beginnings. In Early Puebloan Occupations in the Chaco Region, Volume I: Excavations and Survey of Basketmaker III and Pueblo I Sites, Chaco Canyon, New Mexico, edited by Thomas C. Windes, pp. 663-744. Arizona State Museum Archaeological Series 210. University of Arizona, Tucson.

Wyatt, Barbara

2009 The Components of a Historic Context: A National Register White Paper. Electronic document, http://www.nps.gov/nr/publications/guidance/ NR workshop 3-11-09/White paper on historic context 4-09.doc. Accessed September 8, 2015.

\section{Contributor Notes}

Richard Wilshusen (Ph.D. University of Colorado) has 40 years of experience as a field archaeologist, instructor, curator, contractor, and administrator. He has worked with universities, cultural resource management firms, state and federal government, and tribes. Wilshusen is best known for his research on public archaeology, early Pueblo village formation, Southwestern migration pathways, early great house communities, and Navajo ethnogenesis. He was originally trained as a cultural anthropologist, but has made his living as an archaeologist.

ORCiD

https://orcid.org/0000-0002-4708-3232 